\title{
De la identidad a la intimidad: el desarrollo de Mercedes $^{1}$
}

\author{
Isabel Maria Gonzalez Duarte da Cunha² \\ Mem Martins, Portugal
}

\begin{abstract}
En la adolescencia, la identidad se encuentra en construcción, algo que solo es posible de una forma relacional, permitiendo significar e integrar lo nuevo y lo desconocido. A propósito de la identidad, me propongo pensar sobre el desarrollo de Mercedes, una preadolescente de 12 años que presenta una patología de la identidad traducida en laceraciones provocadas en su propio cuerpo.

La realización de una psicoterapia relacional ha sido fundamental para la co-construcción de un espacio diferenciador, facilitador de la comunicación, fundamental para la construcción de su identidad, permitiendo descubrir su intimidad, abriendo el campo de la fantasía, potenciando el diálogo consigo misma y creando un espacio diferenciador del Yo en la relación con el(los) Otro(s).
\end{abstract}

Palabras clave: identidad, adolescencia, redes sociales, psicopatología, intimidad.

During adolescence, the self-identity is under construction, something only possible in a relational way, which allows the signification and the integration of the new and the unknown. Thinking on identity the author proposal is to focus about the 12 years old Mercedes development, a preadolescent that presents a pathology of identity, translated in mutilations on her body.

The use of a relational psychotherapy has been fundamental to the co-construction of a differentiating space, that allowed a better communication, fundamental for the construction of her identity, enable the discover her intimacy, open the field for fantasy, boost the dialog with herself and created a differentiating space of the I and the relationship with the Other.

Key Words: identity, adolescence, social networks, psychopathology, intimacy.

English Title: From identity to intimacy: the development of Mercedes

\section{Cita bibliográfica / Reference citation:}

Duarte Da Cunha, Isabel María G. (2019). De la identidad a la intimidad: el desarrollo de Mercedes. Clínica e Investigación Relacional, 13 (1): 243-250. [ISSN 1988-2939] [Recuperado de www.ceir.info ] DOI: $10.21110 / 19882939.2019 .130115$

\footnotetext{
${ }^{1}$ Este artículo se basa en una presentación realizada en la VIII Simposio de la Sección de Psicoterapia Psicoanalítica: "Intimidad e identidad en la cultura de la inmediatez" en Noviembre 2018 en Sevilla.

2 PhD., Psicóloga Clínica, Psicoterapeuta, miembro de IARPP International y de IARPP España y miembro del Equipo de las Vulnérabilités, de Le Centre de Recherches sur les Fonctionnements et Dysfonctionnements Psychologiques, de la Universidad de Roven. Ejerce clínica en consulta privada y en Instituciones Sanitarias privadas. Rua Florbela Espanca 32 R/C A 2725-575 Mem Martins, Portugal isabelmgdc@gmail.com
} 
En la sociedad actual el ritmo es vertiginoso, los adolescentes están expuestos a numerosos desafíos y diferentes estímulos que se desmultiplican a cada momento, siendo cada vez más difícil para las familias desempeñar sus funciones parentales, a fin de hacer posible una buena construcción de la identidad y de los procesos de identificación de sus hijos.

Hoy en día, es fundamental pensar la adolescencia recurriendo a los enfoques que representan los procesos mentales que están en curso durante este período de desarrollo (Braconnier, 1985), así como aquellos que permiten la comprensión de los fenómenos psicopatológicos (Marcelli \& Braconnier, 2004), que pueden estar inscritos en una dinámica relacional, de/en transformación, un espacio de co-construcción, esencial para la construcción de una relación intra e interpsíquica (Brown, 2011).

No olvidemos que la identidad es un fenómeno relacional (Coderch, 2014) que se construye en la adolescencia sin la cual no es posible dar sentido y significado a los intensos movimientos de identificación proyectiva para integrar en el crecimiento lo nuevo y lo desconocido. En la comunicación que hoy os presento propongo que reflexionemos sobre Mercedes, una preadolescente de 12 años que, con la ayuda de la psicoterapia, ha sido capaz de construir su identidad y descubrir su intimidad.

\section{La magnitud del encuentro.}

A principios de año, después de las vacaciones de Navidad, en mi consulta de Psicología Clínica, Mercedes se presenta acompañada por su madre: ésta ha descubierto las laceraciones que su hija se infligió por los brazos y piernas. Sus padres se encuentran divorciados desde que ella tenía cuatro años, de modo que su madre ostenta su guardia parental, pasando los fines de semana alternados con el padre. Todos se llevan bien y la madre se disculpa de inmediato por la ausencia del padre en la primera consulta, está trabajando.

Mercedes tiene una sonrisa dulce y un semblante angelical, sus rosetas contrastan con la postura firme y decidida con que se presenta. Describe su falta de autenticidad con su madre, por la dificultad que tiene en poder expresar libremente lo que siente y piensa. Hace una crítica feroz a la forma en que su madre la mira, como a una niña, no siendo libre para poder ponerse la ropa que le gusta, más moderna, como la de sus amigas; por el contrario, su madre la hace vestir esos "vestidos" que solo a ella le gustan.

Procura tener con su padre una complicidad y una relación de exclusividad, la cual es perjudicada por la presencia de su madrastra, con quien se lleva mal, no consiguiendo 
diferenciar lo que siente y piensa de lo que son los acontecimientos de la realidad, que están en la base de la tensión entre ambas: el descubrimiento de lo femenino y de la sexualidad.

La madre está terriblemente asustada por los horrores que circulan en las redes sociales, el juego de la "ballena azul". Muy cerrada en su visión de lo sucedido, está segura de que su hija ha sido incitada a jugar la "ballena azul", por lo que, a su juicio, solo eso justifica las laceraciones que tiene su hija en su cuerpo, algo que le han obligado a hacerse de afuera, $y$ nada que pueda ser reflejo del malestar de su mundo interno.

En cuanto a las laceraciones, Mercedes se refiere a ellas desde hace 2 años, cuando terminó su primera relación amorosa. No obstante, para sus padres es algo reciente: lo descubrieron en uno de sus muchos momentos de tensión que últimamente tienen debido a sus nuevos intereses habituales de la preadolescencia. Estos momentos de tensión suscitan una fuerte tensión con su madre, que le prohíbe todo lo que le gusta, como por ejemplo salir con sus amigas. Es alumna de $6^{\circ}$ de Educación Primaria en un centro público. Cuando llegó a casa para las vacaciones de Navidad, sus notas eran peores a las del año pasado, siendo ésta otra de las preocupaciones de su madre, su poco rendimiento escolar.

\section{Un rostro sin cuerpo.}

La adolescencia es un periodo de desarrollo, durante el cual ocurren las fases que dan lugar al encuentro con el objeto heterosexual, llevando al abandono de las posiciones narcisista y bisexual (Bloss, 1998). El cuerpo del adolescente puede ser considerado como un objeto transitorio de las múltiples pulsiones libidinales y agresivas, situándose entre el objeto externo y los objetos internos de la fantasía, que son el lugar de protección de los fantasmas (Marcelli \& Braconnier, 2004).

Desde el primer encuentro con Mercedes, es notoria la existencia de un problema de identidad, con la falta de límites psíquicos que se traducen en una fuerte descarga en su cuerpo, sentido a la vez, como algo familiar y extraño. Un lugar privilegiado de expresión, un punto de encuentro entre su interior y el exterior, un marco de los límites (Jeammet, 1980), un lugar de afirmación de la identidad, surgiendo las laceraciones, como designa Marcelli \& Braconnier (2004), como una exploración de sus propios límites.

El rostro sencillo de Mercedes, su sonrisa dulce, parece esconder el dolor que comunica con su cuerpo. Semejante a la imagen de Nuestra Señora de las Mercedes, protectora de los esclavos y Patrona de su liberación, ella tiene un rostro que traduce el dolor y un cuerpo oculto por su manto. Mercedes tiene un "rostro sin cuerpo", sus expresiones faciales son expresivas y afectuosas, pero no existe un cuerpo, una vez que éste es sentido al mismo 
tiempo como familiar y extraño, es en simultáneo algo que le pertenece pero proyecta el de Otro.

La madre de Mercedes presenta una gran dificultad en leer la realidad, mostrando comportamientos muy desajustados con su hija, la relación entre ambas se encuentra puntuada por una gran dificultad de separación, existe entre ambas una indiferenciación, los límites no están definidos, lo que suscita una gran confusión traducida en los fuertes movimientos de identificación proyectiva, funcionando el cuerpo de Mercedes como una pantalla de estos movimientos y las laceraciones una traducción concreta de su necesidad de separación.

El padre es una persona afectiva, con una historia de vida marcada por acontecimientos traumáticos, una familia disfuncional, un pasado con drogas, tuvo una gran dificultad para construirse. Describe su impotencia para conseguir separar madre e hija, uno de los motivos por los que solicitó el divorcio hace ocho años. Mercedes busca un lugar especial junto a su padre, de reconocimiento y valorización, pero la rivalidad existente con su madrastra es muy intensa, no dándose cuenta de cómo exige una relación de exclusividad, donde puedan existir apenas los dos, en una lógica de fusión, con un carácter algo incestuoso.

En las primeras sesiones, Mercedes habla asustada de su proximidad con una amiga que está jugando al juego de la "ballena azul", con una mezcla de curiosidad y miedo, quedando la duda si habla de su amiga o de sí misma, sin límites, desafiando el peligro. Las acciones de Mercedes se encuentran descontroladas, hace cosas para no pensar en las cosas que despiertan con la proximidad de la entrada en la adolescencia, su incapacidad de ser autónoma, la necesidad de ser aceptada por el(los) Otro(s) y el deseo de vivir su sexualidad. En este contexto ha sido fundamental la realización de un trabajo psicoterapéutico relacional, permitiendo la integración de cuestiones de su identidad.

En los últimos años, en el terreno de la Psicología asistimos a un cambio fundamental en la manera de entender la relación paciente/terapeuta, como un campo intersubjetivo formado por la interacción de la subjetividad del paciente y del analista que crean un tercer espacio psicológico, que no pertenece ni a uno ni a otro, sino a ambos, que constituye el campo intersubjetivo, co-construido por las dos mentes presentes en el proceso (Coderch de Sans, 2018). 


\section{El espacio terapéutico: la construcción de la intimidad.}

El inicio de la psicoterapia con Mercedes se caracteriza por una enorme dificultad de separación de lo materno. El espacio terapéutico es constantemente invadido y no para de llamar por teléfono, ya sea porque se ha vuelto a infligir laceraciones o solamente porque ha amenazado a su madre que lo iba a hacer; cuestiona continuamente la forma como la madre la educa.

Sin embargo, desde el primero momento, la relación con Mercedes está pautada por la confidencialidad, ella se siente segura con el secreto profesional hacia sus padres. Según Castaño (2014), una relación basada en la intimidad necesita del desarrollo de la confianza y la seguridad. Ésta se va instalando a medida que el decir del paciente, verbal y no verbal, va siendo escuchado por otro, el terapeuta, que le ayuda a escucharse a sí mismo, permitiéndole construir lo que designa como un "espacio común".

Con el inicio de la terapia, uno de los primeros movimientos de Mercedes fue la necesidad de tener su propio espacio físico para dormir, dejando la cama de su madre donde siempre dormía, realizando un movimiento de separación de la espiral tóxica donde estaba confinada, cortando simbólicamente con el cordón umbilical, lo que solo fue posible durante la construcción de su espacio mental.

Con el transcurso de la psicoterapia, la tensión entre madre e hija va en aumento, llevando a su padre a solicitar la custodia compartida, con guarda en semanas alternas. La adaptación a las nuevas reglas y a una dinámica de responsabilidad estuvo en el origen de la (re)construcción de la relación con su padre, en la que pueden compartir juntos sus gustos musicales y cinematográficos. Su madrastra ya no es "drastra", es una mujer sencilla que la introduce en las lógicas del deseo de lo femenino, ayudándola a saber cómo cuidar de su cuerpo, ahora que empiezan a observarse los primeros cambios y desarrolla sus formas de mujer.

Al finalizar el año lectivo, la necesidad de cambio al instituto provoca una nueva fuente de tensión. No obstante, la forma en que Mercedes acepta este cambio es muy distinta a la de antaño, siente angustia, pero no la traduce en el cuerpo, no se inflige laceraciones, procede de una forma más constructiva, negociando con sus padres su autonomía, la posibilidad de ir sola al instituto y quedarse unos minutos con su nuevo grupo de amigos. Para Fleming (1997), la autonomía es una adquisición fundamental, tanto para la apropiación del cuerpo como para la conquista de un espacio mental, que permite pensar y relacionarse fuera de la familia, donde el grupo de amigos es el contrapunto a la familia. 
Llevábamos un año de terapia y la adolescencia de Mercedes transcurría con una duplicidad de movimientos, unos alrededor de la organización y del crecimiento y otros más disruptivos que traducen la inestabilidad de su identidad, reveladores de una incapacidad para tener su intimidad, algo que está muy presente en nuestra sociedad actual y claramente asociada a una lógica parental donde domina el control, ya que la construcción de la intimidad implica escucharse desde dentro, encontrar la propia voz en la oscuridad, contactar con el sentido y el significado (Pardo, 2004). Esto es lo que Mercedes empieza hacer dibujando, haciendo dibujos de Naruto, un anime, un personaje sexualmente poco diferenciado, que traduce su propia ambivalencia e indiferenciación.

A lo largo de la terapia, el trabajo de los movimientos transferenciales y contratransferenciales ha sido una herramienta fundamental, tanto para la clarificación de mis limitaciones, como también para el camino a la creatividad de Mercedes: el descubrimiento y el desarrollo de recursos que desconocía y que le han permitido el surgimiento de una "Transformación Progresiva" en el camino hasta el "O" de Bion (1982), que se traduce en un aumento de la capacidad de simbolización y de abstracción (Duarte, 2017).

A través de la relación conmigo, como terapeuta, ha sido posible vivir la experiencia de intimidad consigo misma y con el Otro. La intimidad es algo que pertenece exclusivamente a la vida privada de cada uno, algo a lo que no puede acceder más que la familia o el terapeuta, porque es un secreto y solo se puede experimentar en soledad y aislamiento. La capacidad de conectar con la intimidad del Otro permite el reconocimiento del sujeto, lo que facilita el compartir, caminar junto a, desear, conectar, rompiendo automatismos y perdiendo la timidez (Castaño, 2014).

Este es el punto de partida para una nueva etapa que empieza al ritmo del beatbox, con la música rap, fuente de fuertes mensajes de cariz sexual y agresivo, que Mercedes reproduce a una velocidad vertiginosa. Es en este contexto que empieza su relación de pareja más larga, después de amoríos que cambiaban a cada sesión, completamente idealizados. Empieza una relación de gran complicidad con un colega, tres años mayor que ella, donde la música y la práctica deportiva son dos puntos de conexión.

\section{Consideraciones Finales.}

En el trabajo psicoterapéutico realizado con Mercedes ha sido fundamental la regularidad y la constancia del setting, ya que ha permitido el desarrollo de la creatividad, surgiendo nuevas formas de expresión. No menos importante ha sido el papel de su familia, que se ha 
mantenido en unísono, firme en sus decisiones respecto a ella, transmitiendo la confianza y la seguridad necesarias para su mejor desarrollo.

El espacio psicoterapéutico ha sido fundamental para la construcción de un espacio diferenciador, en el que se pueden reconocer los límites y recapacitar, haciendo ajustes a la realidad, dando un sentido a sus comportamientos autolesivos que han cesado, permitiendo el desarrollo de una relación de comunicación, favoreciendo así la toma de consciencia de los procesos inconscientes, beneficiando los procesos de transformación y potenciando el crecimiento mental (Ferro, 2009).

Entender a Mercedes y conseguir su cambio no se logra por la exclusiva comprensión de su sufrimiento, sino por la relación que se va construyendo entre nosotras, juntas en un juego creativo. Con el transcurso de la psicoterapia, Mercedes iba estando más segura de su identidad, siendo posible la construcción de su intimidad, lo que Castaño (2004) designó como un espacio subjetivo de la fantasía, una barrena subjetiva en la que uno puede refugiarse, ensimismarse y dialogar consigo, esto es, un lugar diferenciador del Yo, en la relación con el(los) Otro(s).

\section{REFERENCIAS}

Bion, W.R. (1982). As transformações. A mudanças do aprender para o crescer. Rio de Janeiro: Imago Editora.

Blos, P. (1962/1998). Adolescência. Uma interpretação Psicanalítica. São Paulo: Martins Fontes.

Braconnier, A. (1985). Ruptures et séparations. Adolescence, 3, 1. 5-19.

Brown, L. (2011). Intersubjective Processes and the Unconscious. An integration of Freudian, Kleinian and Bionian Perspectives. London: Routledge.

Castaño, R. (2014). La psicoterapia como un espacio de juego y una experiencia de intimidad. In Coderch, J. (2014). Avances en Psicoanálisis Relacional. Nuevos campos de exploración para el psicoanálisis, (pp. 419-457). Madrid: Ágora Relacional.

Coderch, J. (2014). La Búsqueda de la Identidad. In Coderch, J. (2014). Avances en Psicoanálisis Relacional. Nuevos campos de exploración para el psicoanálisis, (pp. 419457). Madrid: Ágora Relacional.

Coderch de Sans, J. (2018). Presentación del livro de Juan José Martínez Ibáñez, El enigma de la angustia. Clínica e Investigación Relacional, 12 (1): 163-171.

Duarte, I. (2017). O Tornar-se Adolescente Através Do Rorschach. Lisboa: Chiado Editora. 
Ferro, A. (2009). Mind Works. Technique and Creativity in Psychoanalysis. London: Routledge.

Fleming, M. (1997). Adolescência e Autonomia. O desenvolvimento psicológico e a relação com os pais. Porto: Edições Afrontamento.

Jeammet, P. (1980). Réalité externe et réalité interne importance et spécificité de leur articulation à l'adolescence. Revue Française de Psychanalyse. 3-4, 481-521.

Marcelli, D. \& Braconnier, A. (2004). Adolescência e Psicopatologia. Lisboa: Climepsi.

Original recibido con fecha: 28/11/2018 Revisado: 30/01/2019 Aceptado: 30/03/2019 